Check for updates

Cite this: Anal. Methods, 2018, 10 , 4225

Received 6th July 2018

Accepted 14th August 2018

DOI: 10.1039/c8ay01488d

rsc.li/methods

\section{XPS investigation of the vacuum interface of an ionic liquid under triangular electrical excitation for slow transients $\uparrow$}

\author{
Merve Taner Camci, (D) $\dagger^{* a}$ Burak Ulgut, (D) ${ }^{a}$ Coskun Kocabas $\S^{b}$ and Sefik Suzer (D) ${ }^{a}$
}

We report on an XPS investigation of slow transient charge imbalance at the vacuum interface of an ionic liquid, by imposing a triangular electrical excitation to two gold electrodes having an ionic liquid in between. Intensity ratio of the two $\mathrm{N}$ 1s peaks of the anion and the cation undergoes a total difference of up to $\sim 20 \%$ as the IL is slowly electrified between -5 to $+5 \mathrm{~V}$.

Ionic liquids (ILs) are molten salts at room temperature composed purely of ions with almost zero vapor pressure in the liquid phase, providing high density, electrical conductivity and mobility of ions. ${ }^{1,2}$ The chemical and physical properties of ILs are mostly governed by the type of anion and cation combinations as they consist only of charged groups. ${ }^{3,4}$ Moreover, since the charged fragments are mobile under ambient conditions, susceptible to structural rearrangement, they render different properties than the electrolytes that contain dissolved ions and/ or neutral molecules in an electrochemical system. ${ }^{5}$ As the physicochemical properties of ILs can be tuned, usage of ILs in conventional systems enables significant performance in advanced applications such as electrochemical devices, ${ }^{6-8}$ solar cells ${ }^{9}$ or catalysis. ${ }^{10}$ The structural rearrangement of the ionic fragments closer to the interfacial region is a complicated subject $^{\mathbf{1 1}}$ with plenty of room for enhancing our basic understanding. Hence, investigation on probing the preferential rearrangements of the anions and cations is of interest for further developments in fundamental understanding as well as towards their applications. Therefore, a multitude of

\footnotetext{
aDepartment of Chemistry, Bilkent University, Ankara 06800, Turkey.E-mail: mtaner@ fen.bilkent.edu.tr

${ }^{b}$ Department of Physics, Bilkent University, Ankara 06800, Turkey

$\dagger$ Electronic supplementary information (ESI) available: Additional experimental details, additional information on data gathering with TRW excitation, double-checking on the consistency of intensity ratio change of the $\mathrm{N} 1 \mathrm{~s}$ peaks, estimation of the surface voltage developments with electrification. See DOI: 10.1039/c8ay01488d

\$ CNRS Institut Charles Sadron, Strasbourg 67034, France.

$\S$ School of Materials, The University of Manchester, Manchester M13 9PL, UK.
}

experimental as well as computational/simulation techniques have recently been devoted to investigation of the interfacial properties of the ILs, especially towards formation of the electrical double layer (EDL) at electrified interfaces. This subject has recently been thoroughly reviewed by Fedorov and Kornyshev. ${ }^{12}$

The most crucial sought-after information is the electroneutrality breakdown and/or kinetics of restructuring of the ionpairs of the ILs at electrified interface. In addition to a number of electrochemical characterization techniques, ${ }^{13}$ others, such as: sum-frequency generation (SFG) ${ }^{14,15}$ infrared, ${ }^{16,17}$ Raman, ${ }^{18}$ and NMR spectroscopic, ${ }^{19,20}$ surface plasmon resonance, ${ }^{13} \mathrm{X}$-ray reflectivity, ${ }^{21-25}$ and $\mathrm{AFM}^{26}$ measurements have been utilized to characterize the chemical nature of the changes taking place at electrochemical interfaces. The common findings of these experimental investigations are the existence of an unexpectedly slow response of ions $\left(10^{-1}\right.$ to $\left.10^{2} \mathrm{~s}\right)$ together with a hysteresis behavior, both of which have been confirmed by extensive simulation studies..$^{1527-31}$ In addition to the electrochemical analysis of the interfaces, electro-wetting properties of various ionic liquids are studied under AC potential at different frequencies and compared to DC potential responses. ${ }^{32}$

Since ILs have near zero vapor-pressure, X-ray photoelectron spectroscopy (XPS) is well suited and has been extensively used to characterize physicochemical properties of numerous ionic liquids and their interfaces. The superb chemical specificity of the technique, together with a variable depth information in the $n m$ range, achieved by recording the data at grazing angles (Angle-Resolved XPS or ARXPS) has yielded a wealth of information about structure and reactivity of the ILs, ${ }^{33,34}$ and the subject had been reviewed. ${ }^{35-37}$ Furthering their previous work in a recent paper, Kolbeck et al. have summarized their comprehensive analyses of the surface composition of numerous functionalized and non-functionalized ionic liquids, which revealed pivotal information about the intricate interplay between intermolecular and electrostatic interactions. ${ }^{38}$ However, most XPS measurements have been carried out without deliberate electrification of surfaces, except for the 
pioneering work of Foelske-Schmitz et al., where it was demonstrated that the IL/vacuum interfaces could be electrified and the IL complied to the electrochemical potential imposed..$^{39-42}$ Herein, we present a similar XPS study of one particular ionic liquid, $N, N$-diethyl- $N$-methyl- $N$-(2-methoxyethyl)ammonium bis(trifluoro-methane-sulfonyl)imide (DEME-TFSI) placed between two gold electrodes, where one of the electrodes is subjected to various electrical excitation and the other is grounded to create an electrified IL/vacuum interface. DEME-TFSI was chosen for ease of XPS analysis, since it has two nitrogen atoms one with a positive (quaternized ammonium) and the other with a negative (imide) charge, representative of the cation and the anion fragments respectively, and the two $\mathrm{N}$ 1s peaks are conveniently resolved from each other. ${ }^{43}$ The uniqueness of the present study is the ability to validate that electrical excitation induces charge imbalance between the ion-pairs, revealed by the intensity changes of the $\mathrm{N}$ 1s peaks of the anion and the cation under the slow TRW excitation, and not under DC potential, as we will show below.

One particular feature of XPS measurements is its ability to provide electrical information about the sample by recording the data under application of external electrical stimuli, which has been extensively used by our group and others. ${ }^{4-47}$ Since it is anticipated that a slow rearrangement of ions will take place at the vacuum interface, an equally slow varying electrical signal can be used to induce rearrangement, yet allow recording of XPS data in transient. Therefore, a triangular wave excitation was adopted, with a $5 \mathrm{~V}$ amplitude and $1 \mathrm{mHz}$ frequency, which has been optimized to provide the information sought-after; i.e. the transient but slow intensity variations of the cationic to anionic peaks as a function of the polarity and the degree of the electrification. For this purpose, Au electrodes are deposited on a poly-ethylene (PE) porous polymer membrane, and the ionic liquid DEME-TFSI is injected underneath the membrane. The electrical excitation is imposed between the two gold electrodes. XPS measurements are carried out using a Thermo Fisher Kalpha electron spectrometer (see the ESI $\dagger$ section for Experimental details).

A typical XPS survey spectrum, as given in Fig. 1(a), confirms the presence and the stoichiometry of the IL through the peaks of $\mathrm{C} 1 \mathrm{~s}, \mathrm{~N} 1 \mathrm{~s}, \mathrm{O} 1 \mathrm{~s}, \mathrm{~F} 1 \mathrm{~s}$, and $\mathrm{S} 2 \mathrm{p}$ and $2 \mathrm{~s}$. The slow response of the ionic liquid to the external stimulus is also observable through recording the $\mathrm{F}$ 1s peak in the snap-shot mode with 1 second intervals as shown in the same figure (Fig. 1(c)) by application of $5 \mathrm{~V}$ square-wave (SQW) excitation with $10 \mathrm{mHz}$ frequency. For those analyses, the most intense $\mathrm{F}$ 1s peak was chosen for a favorable signal-to-noise ratio, which only represents the anionic fragments.

Of particular interest is the well-resolved $\mathrm{N}$ 1s peaks representing the anionic $-\mathrm{N}^{-}$and the cationic $-\mathrm{N}^{+}$fragments in its structure, with the corresponding binding energies of 402.7 and $399.5 \mathrm{eV}$, respectively. ${ }^{43}$ In all of the samples investigated in this work, before application of the electrical bias we had measured the intensity of these two peaks to be very close to each other with a ratio of $1.00 \pm 0.05$ as shown in Fig. 1(b). Through the application of the triangular wave, where the external potential is scanned linearly in time from $-5 \mathrm{~V}$ to $+5 \mathrm{~V}$ with a period of
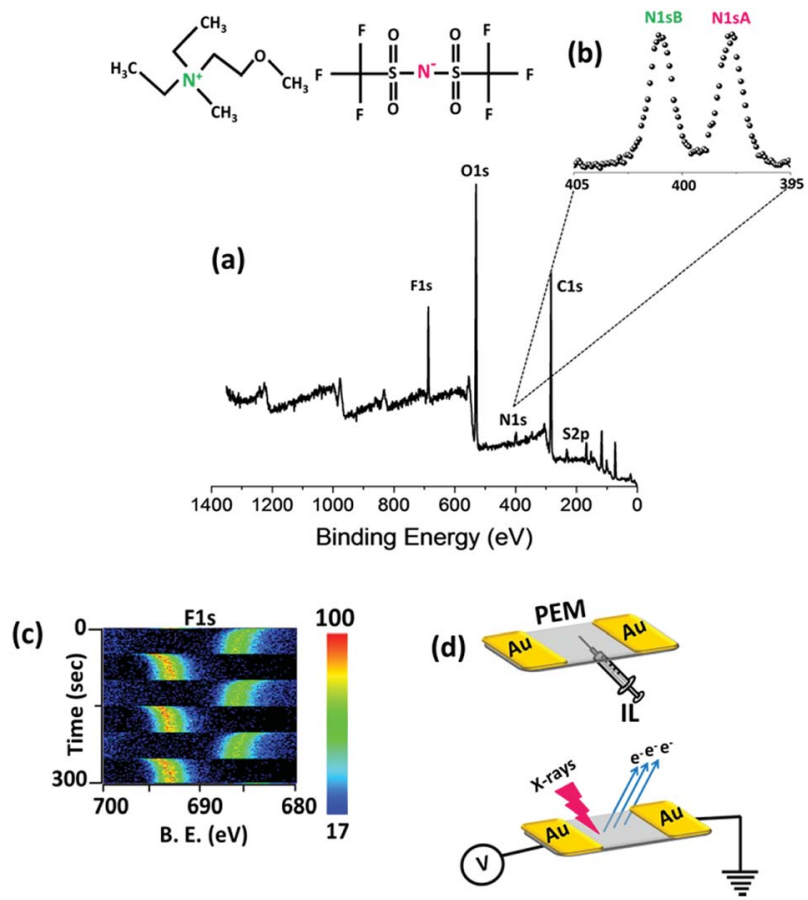

Fig. 1 (a). Survey XP spectrum of the ionic liquid DEME-TEFSI, and (b) the corresponding $\mathrm{N}$ 1s region. (c) Time-resolved $\mathrm{F}$ 1s spectral region recorded with 1s time-intervals under a $5 \mathrm{~V} 10 \mathrm{mHz}$ SQW excitation. (d) Schematic of the device and the experimental set-up.

1000 seconds, the peak position also changes, which can be used to reflect the sign and the magnitude of the electrification. The ratio of the two $\mathrm{N} 1 \mathrm{~s}$ peaks is expected to follow the reorientation in the anionic and cationic fragments with respect to the developed charge. However, extreme care has to be exercised to record variations faithfully, since during data acquisition the extent of the electrification also changes. It is important to note that on the one hand, a time varying stimuli is absolutely necessary to induce and monitor the transient ion rearrangement/motion, which is in the order of several tens of seconds, on the other hand, recording a reliable spectral region also requires a finite time window rather than the DC potential which has an infinite time window. As a possible practical solution of this dilemma, we record the $\mathrm{N}$ 1s region (390-410 eV) in two different scans, as given in Fig. 2.

In the first round, the spectrum is recorded in order of increasing binding energy of $0.2 \mathrm{eV}$ steps with a dwell time of $100 \mathrm{~ms}$, and in the second round the same region is recorded in order of decreasing binding energy, resulting in a time difference of 16 seconds between the two spectra. Details of data gathering and the representative spectra are given in the ESI section, as Fig. S2 and S3. $\dagger$ Extracted data are given in Fig. 3 as two different spectral evolutions in time, together with their time sequences depicted schematically.

Each spectrum is fitted to two $\mathrm{N}$ 1s peaks and the binding energy position, area and also the intensity ratio of them are computed separately. As revealed by the figure the $\mathrm{N}^{-} / \mathrm{N}^{+}$ratio displays a total of $\sim 20 \%$ intensity change while the IL is subjected to a slowly varying electrification from -5 to $5 \mathrm{~V}$, which is 


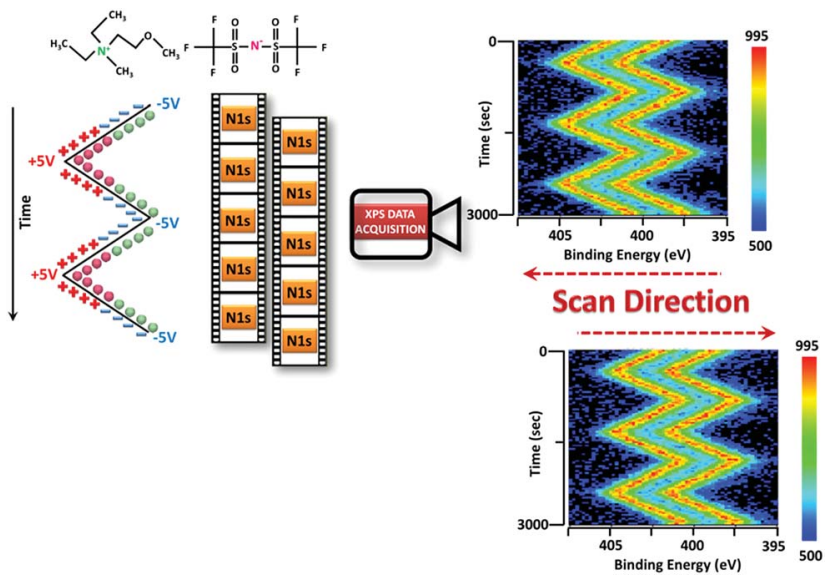

Fig. 2 Time-resolved $\mathrm{N}$ 1s spectral region recorded in the forward and reverse directions, while the same $5 \mathrm{~V}$ TRW excitation is imposed from one of the metal electrodes.
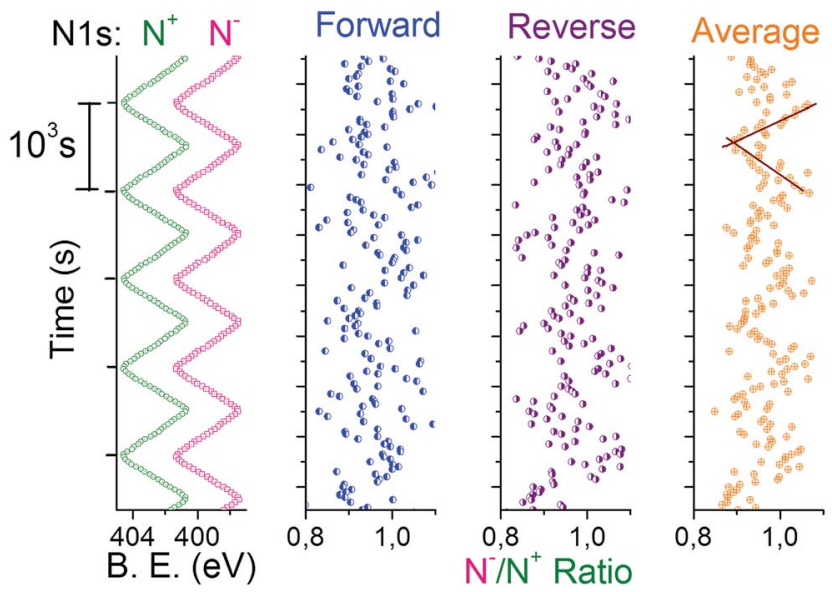

Fig. 3 Extracted B.E. positions of the two $N$ 1s peaks, together with computed intensity ratio of them, while a $5 \mathrm{~V}$ TRW excitation is imposed.

reversible and reproducible for several hours. Moreover, although the measured intensities of the $\mathrm{N} 1 \mathrm{~s}$ and also the other IL related peaks showed some random variations across the electrodes, consistent $20 \%$ variations were also measured at different lateral positions. Since the measured $20 \%$ difference corresponds to the changes at the extreme polarization points, one can safely infer that the cation/anion ratio changes in the range of 0.9-1.1 (see the ESI $\dagger$ section for details). A similar finding was also observed and has recently been reported by us, during voltage driven intercalation of a multi-layered graphene electrode by the same IL used in the present work. ${ }^{48}$

A simple order of magnitude estimate for the electrical potential based on the measured charge excess at or near the vacuum interface leads to an unexpectedly large electrostatic potential development (see the ESI $\dagger$ section) using the bulk dielectric constant of the IL. ${ }^{49}$ This would also point out that this probed region near the surface transiently carries very high amounts of excess charge that has relaxation times on the order of tens of seconds, during a voltage sweep, which is the very reason that enabled us record the intensity variations. One simple argument is that, this high charge excess may indicate that the top $\sim 6 \mathrm{~nm}$ portion of the surface of the ionic liquid, corresponding to the probe depth of the XPS, has a very different dielectric environment than the bulk. ${ }^{48,50}$ An alternative explanation could be due to low ionicity of the IL, meaning that only a small fraction of ions are independent, and the majority behaves like an inert ion-pair, as advocated by recent experimental and theoretical work. ${ }^{51-53}$

In summary, we show that XPS can detect, locate, and quantify ion imbalance and rearrangement via electrostatic charging of the ionic liquid, if interfaces are properly electrified. Needless to say that further experimental and theoretical work are definitely needed to clarify and extend our findings, but one thing is clear that XPS can definitely bring a fresh and chemically resolved perspective.

\section{Author contributions}

The manuscript was written through contributions of all authors. All authors have given approval to the final version of the manuscript.

\section{Conflicts of interest}

There are no conflicts to declare.

\section{References}

1 R. D. Rogers and K. R. Seddon, Science, 2003, 302, 792-793.

$2 \mathrm{H}$. Ohno, Electrochemical aspects of ionic liquids, John Wiley \& Sons, 2011.

3 F. Gharagheizi, M. Sattari, P. Ilani-Kashkouli, A. H. Mohammadi, D. Ramjugernath and D. Richon, Chem. Eng. Sci., 2013, 101, 478-485.

4 S. Zhang, N. Sun, X. He, X. Lu and X. Zhang, J. Phys. Chem. Ref. Data, 2006, 35, 1475-1517.

5 R. Hayes, G. G. Warr and R. Atkin, Chem. Rev., 2015, 115, 6357-6426.

6 Y. Lu, K. Korf, Y. Kambe, Z. Tu and L. A. Archer, Angew. Chem., Int. Ed., 2014, 126, 498-502.

7 I. Osada, H. de Vries, B. Scrosati and S. Passerini, Angew. Chem., Int. Ed., 2015, 55, 500-513.

8 F. Valentini, D. Roscioli, M. Carbone, V. Conte, B. Floris, G. Palleschi, R. Flammini, E. Bauer, G. Nasillo and E. Caponetti, Anal. Chem., 2012, 84, 5823-5831.

9 M. Gorlov and L. Kloo, Dalton Trans., 2008, 2655-2666.

10 T. Matsuda, N. Taccardi, J. Schwegler, P. Wasserscheid, H. P. Steinrück and F. Maier, ChemPhysChem, 2015, 16, 1873-1879.

11 R. Hayes, G. G. Warr and R. Atkin, Chem. Rev., 2015, 115, 6357-6426.

12 M. V. Fedorov and A. A. Kornyshev, Chem. Rev., 2014, 114, 2978-3036.

13 N. Nishi, Y. Hirano, T. Motokawa and T. Kakiuchi, Phys. Chem. Chem. Phys., 2013, 15, 11615-11619. 
14 C. Y. Peñalber and S. Baldelli, J. Phys. Chem. Lett., 2012, 3, 844-847.

15 S. Xu, S. Xing, S.-S. Pei, V. Ivanišš̌ev, R. Lynden-Bell and S. Baldelli, J. Phys. Chem. C, 2015, 119, 26009-26019.

$16 \mathrm{~W}$. Zhou, S. Inoue, T. Iwahashi, K. Kanai, K. Seki, T. Miyamae, D. Kim, Y. Katayama and Y. Ouchi, Electrochem. Commun., 2010, 12, 672-675.

17 K. Motobayashi, K. Minami, N. Nishi, T. Sakka and M. Osawa, J. Phys. Chem. Lett., 2013, 4, 3110-3114.

18 K. Iwata, H. Okajima, S. Saha and H.-o. Hamaguchi, Acc. Chem. Res., 2007, 40, 1174-1181.

19 Z.-X. Luo, Y.-Z. Xing, Y.-C. Ling, A. Kleinhammes and Y. Wu, Nat. Commun., 2015, 6, 6358.

20 J. M. Griffin, A. C. Forse, W.-Y. Tsai, P.-L. Taberna, P. Simon and C. P. Grey, Nat. Mater., 2015, 14, 812.

21 E. Sloutskin, B. M. Ocko, L. Tamam, I. Kuzmenko, T. Gog and M. Deutsch, J. Am. Chem. Soc., 2005, 127, 7796-7804.

22 M. Mezger, B. M. Ocko, H. Reichert and M. Deutsch, Proc. Natl. Acad. Sci. U. S. A., 2013, 110, 3733-3737.

23 M. Mezger, H. Schröder, H. Reichert, S. Schramm, J. S. Okasinski, S. Schöder, V. Honkimäki, M. Deutsch, B. M. Ocko and J. Ralston, Science, 2008, 322, 424-428.

24 A. Uysal, H. Zhou, G. Feng, S. S. Lee, S. Li, P. T. Cummings, P. F. Fulvio, S. Dai, J. K. McDonough and Y. Gogotsi, J. Phys.: Condens. Matter, 2015, 27, 032101.

25 A. Uysal, H. Zhou, G. Feng, S. S. Lee, S. Li, P. Fenter, P. T. Cummings, P. F. Fulvio, S. Dai and J. K. McDonough, J. Phys. Chem. C, 2013, 118, 569-574.

26 R. Hayes, N. Borisenko, M. K. Tam, P. C. Howlett, F. Endres and R. Atkin, J. Phys. Chem. C, 2011, 115, 6855-6863.

27 B. Bhargava and S. Balasubramanian, J. Am. Chem. Soc., 2006, 128, 10073-10078.

28 R. M. Lynden-Bell, M. G. Del Popolo, T. G. Youngs, J. Kohanoff, C. G. Hanke, J. B. Harper and C. C. Pinilla, Acc. Chem. Res., 2007, 40, 1138-1145.

29 Y. Wang, J. Phys. Chem. B, 2009, 113, 11058-11060.

30 V. Ivaništšev, K. Kirchner, T. Kirchner and M. V. Fedorov, J. Phys.: Condens. Matter, 2015, 27, 102101.

31 C. Merlet, D. T. Limmer, M. Salanne, R. Van Roij, P. A. Madden, D. Chandler and B. Rotenberg, J. Phys. Chem. C, 2014, 118, 18291-18298.

32 Y. S. Nanayakkara, S. Perera, S. Bindiganavale, E. Wanigasekara, H. Moon and D. W. Armstrong, Anal. Chem., 2010, 82, 3146-3154.
33 E. F. Smith, I. J. V. Garcia, D. Briggs and P. Licence, Chem. Commun., 2005, 5633-5635.

34 E. F. Smith, F. J. Rutten, I. J. Villar-Garcia, D. Briggs and P. Licence, Langmuir, 2006, 22, 9386-9392.

35 K. R. Lovelock, E. F. Smith, A. Deyko, I. J. Villar-Garcia, P. Licence and R. G. Jones, Chem. Commun., 2007, 48664868.

36 P. Licence, Angew. Chem., Int. Ed., 2012, 51, 4789-4791.

37 K. R. Lovelock, I. J. Villar-Garcia, F. Maier, H.-P. Steinrück and P. Licence, Chem. Rev., 2010, 110, 5158-5190.

38 C. Kolbeck, I. Niedermaier, A. Deyko, K. R. Lovelock, N. Taccardi, W. Wei, P. Wasserscheid, F. Maier and H. P. Steinrück, Chem.-Eur. J., 2014, 20, 3954-3965.

39 D. Weingarth, A. Foelske-Schmitz, A. Wokaun and R. Kötz, Electrochem. Commun., 2011, 13, 619-622.

40 A. Foelske-Schmitz, D. Weingarth, H. Kaiser and R. Kötz, Electrochem. Commun., 2010, 12, 1453-1456.

41 A. Foelske-Schmitz, P. W. Ruch and R. Kötz, J. Electron Spectrosc. Relat. Phenom., 2010, 182, 57-62.

42 A. Foelske-Schmitz and M. Sauer, J. Electron Spectrosc. Relat. Phenom., 2018, 224, 51-58.

43 S. Men, D. S. Mitchell, K. R. Lovelock and P. Licence, ChemPhysChem, 2015, 16, 2211-2218.

44 M. Camci, P. Aydogan, B. Ulgut, C. Kocabas and S. Suzer, Phys. Chem. Chem. Phys., 2016, 18, 28434-28440.

45 H. Sezen and S. Suzer, Thin Solid Films, 2013, 534, 1-11.

46 B. Bozzini, M. Amati, L. Gregoratti, M. K. Abyaneh, M. Prasciolu, A. L. Trygub and M. Kiskinova, J. Phys. Chem. C, 2012, 116, 23188-23193.

47 C. P. Conger and S. Suzer, Langmuir, 2009, 25, 1757-1760.

48 M. Taner-Camc1, B. Ulgut, C. Kocabas and S. Suzer, J. Phys. Chem. C, 2018, 122, 11883-11889.

49 H. Weingärtner, Angew. Chem., Int. Ed., 2008, 47, 654-670.

50 O. Bondarchuk, A. Morel, D. Belanger, E. Goikolea, T. Brousse and R. Mysyk, J. Power Sources, 2016, 324, 439446.

51 M. A. Gebbie, H. A. Dobbs, M. Valtiner and J. N. Israelachvili, Proc. Natl. Acad. Sci. U. S. A., 2015, 112, 7432-7437.

52 R. Yamamoto, H. Morisaki, O. Sakata, H. Shimotani, H. Yuan, Y. Iwasa, T. Kimura and Y. Wakabayashi, Appl. Phys. Lett., 2012, 101, 053122.

53 D. R. MacFarlane, M. Forsyth, E. I. Izgorodina, A. P. Abbott, G. Annat and K. Fraser, Phys. Chem. Chem. Phys., 2009, 11, 4962-4967. 